\title{
Patient's care and nursery in different diseases
}

\begin{abstract}
A great proportion of healthcare efforts for a chronic or dying patient in a general hospital are both physical supports (mobile and medical assistance) and cognitive/ emotional communication (activity of nursing and spiritual promotion). The spiritual part of medical/health efforts is a common-place for disabled patients. The promotion of the quality and diversity of medical nursing is as important as doctorial areas for patient's recovery and survivals until now. However, currently, nursing activity does not receive enough academic notification and respect (economic benefits) globally. This editorial addresses parts of these medical challenges and highlights their possible trends in the future.
\end{abstract}

Keywords: healthcare, nursing, medical service, modern technology, mathematicians, psycho-analysis
Volume 3 Issue I - 2019

\author{
Da-Yong Lu, 'Yu-Zheng Chen, ${ }^{2}$ Da-Feng Lu, ${ }^{2}$ \\ Jin-Yu Che' \\ 'Shanghai University, Shanghai, China \\ ${ }^{2}$ The Second Hospital of Neijiang District, Sichuan Province, \\ China
}

Correspondence: Da-Yong Lu, Shanghai University, Shanghai 200333, PRC, China, Email ludayong@shu.edu.cn

Received: October 25, 2018| Published: February 12, 2019

\section{Introduction}

\section{Importance}

Today, a half of major diseases are chronic diseases. Their recovery processes are not defined in operation-room (surgery), but getting better in the bedside (therapeutic conventions-drugs, nutrition and instruments) and nursery process (physical or spiritual assistance). A great proportion of healthcare efforts for a chronic or dying patient in a general hospital are both doctors and nursing. ${ }^{1-6}$ Any unilateral activity will greatly undermine therapeutic efforts and patients' recovery.

\section{Major efforts and categories}

Medical care and nursing play critical roles on patient's recovery and disease controls from both physical activity/backup and cognitive/emotional communications. The promotion of the quality and scope of medical healthcare and nursing activity is as important as doctorial treatments for patient's recovery and survivals until now. However, currently, nursing activities in hospitals does not receive enough academic notification and economic respects globally. This editorial addresses parts of these medical challenges and highlights their possible trends in the future.

\section{Relation between major disease and nursery requirement}

There is no nursery activity can be reliant on every medical discipline. Thus, the relationship between major diseases and nursery requirements is given in Table 1 . In the past educational system, nursery education was regarded as uniformity. Nursery work is commonly considered as sub-ordinary and less important. In this stereotypic mindset, nurse can be placed everywhere. This leads to slow progress of nursery science discovery and developments (Table $1)$.

Table I A general picture of nursery services for major diseases

\begin{tabular}{ll}
\hline Disease types & Major targets \\
\hline Infection & Body temperature, isolation and so on \\
Obstetric & Child, mother, Fetus observation \\
Mental disorders & Psychiatric, neurology, cognitive, depression, excite \\
Cancer & Chronic body recovery and emergency \\
Metabolic disease & Food and exercise assistance \\
Orthopedics & Immobile and osteoporosis \\
Cardiovascular & Blood pressure, electrocardiography and angiography \\
Handicaps & Limb/foot, blind, deaf and speechless \\
Pediatric & Helping-hands for the children \\
Gastro-intestinal & Bleed and digests \\
\hline
\end{tabular}

\section{Current limitations}

Current norm of patient's care and nursing are provided by doctors and facility of different hospitals. These medical care and nursing are commonly uniform and hospital-based. Little attention is given to many specific or individualized patients. System developments for these services are relatively slow or neglected in most hospitals. This difference of nursery services requirements of doctors and patients 
makes low or high therapeutic benefits based on nursery systems. It is because hospitals provide nursery services according to their own mindset and available systems. Some patients who have some peculiar custom will greatly affect by those uniform survey systems based on hospital facility. In our opinion, medical care and nursing should be targeted to every patient. Individualized nursing should be established in the future.

\section{Central topics}

\section{Salary promotion}

Entering into this millennium, technical and educational requirements for nurses increase dramatically. However, the income of these healthcare providers (nursery items) increases slowly comparing with doctor's and other technician's salary. Loss of motivation and states from experienced nurses and talents are everywhere. This trend is especially common in developed countries and large cities in developing countries. Nurses on famous hospitals worldwide are commonly well educated. They are capable of providing medical care and service much higher than their assignments in the real clinical settings. The nurse's physical requirement is no less than many types of doctors. Adequate economic increase of healthcare providers and nurses in hospitals is important and indispensable. Cost balance costs between doctors' check up/prescription and patients' nursing activity will be a future challenge.

\section{Efficient promotion}

As mentioned above in medical care, optimizing the resources of personnel and money needs to be established. To provide many supportive activity, guided by experienced nurses might be recommended in some healthcare centres. The importance of experienced nurses is no less than a general doctor in patient's recovery. Their long-term experience is unique and indispensable. This nursery scientific issue needs to be found out.

\section{Grading technical position}

Grading for nurse's activity and technical positions in hospitals may be an effective policy for keeping up the quality of patient's care and getting back of health care talents. Most doctors are commonly too busy to take care of patients in each detail and regulatory monitor. We must respect the commitments of nurses and assistant work. Without these respects of healthcare services, patient's care will be just an un-attainable goal.

\section{Future directions}

\section{Specificity}

Healthcare and nursery work must be specialized. Different divisions of a hospital need different kinds of assistant medical personnel. Like nurses in obstetric, emergency and operation divisions need different and specialized training and practice. Correspondingly, we must provide special funds to experienced nurses (long term of medical services in the hospitals). Also, it is proposed to provide us with opportunity of publication and research funds for nursery science discovery and developments. Only personnel in medical fronts have the ability to find new healthcare solutions. This policy will promote medical services of nursery work in general hospitals globally.

\section{Teamwork in modern medicine}

Therapeutics in the future is no longer a performance and decision- making by doctors alone. ${ }^{7,8}$ Many technical or assistance forces will take part of medical practice for quality boosting-including pharmacologists, pathologists, biochemical technologists, nurses, mathematicians and many others. Without the assistance of these experts, clinical doctors will be narrow-minded and difficult to execute excellent jobs for all patients. This modern tread is unavoidable and eventually executes it globally.

In summary, different types of nursery play key roles in clinical trials, especially chronic diseases, such as HIV/AIDS treatments, ${ }^{9}$ mental diseases, ${ }^{10-13}$ bone disorders, ${ }^{14-17}$ metabolic diseases, ${ }^{18-23}$ cancers $^{24,25}$ and so on.

\section{Conclusion}

Patient's care and nursery play important roles for patient treatments and recovery. In order to promote these kinds of medical and technical work, new policy and creative ideas must be implemented in the future. To conclude, we must respect these kinds of medical services and promote them into new levels.

\section{Acknowledgments}

None.

\section{Conflicts of interest}

The authors declare there is no conflicts of interest.

\section{References}

1. Shamm Ahmad. Diabetes-an old disease, a new insights. USA: Springer Science; 2013:485.

2. Zimmet PZ, Magliano DJ, Herman WH, et al. Diabetes; a 21st century challenge. Lancet Diabetes Endocrinol. 2014;2(1):56-64.

3. Grimaccia F, Kanavos P. Cost, outcome, treatment pathways and challenges for diabetes care in Italy. Global Health. 2014;10(1):58.

4. Lu DY. Personalized cancer chemotherapy, an effective way for enhancing outcomes in clinics. UK: Woodhead Publishing, Elsevier; 2014:84.

5. Lu DY. Suicide risks and treatments, new ideas and future perspectives. New York, US: Nova Science Publishers; 2017:102.

6. Lu DY. HIV/AIDS treatments, fight for a cure. Germany: LAMBERT Academic Publishing; 2017:120.

7. Lu DY, Zhu PP, Lu TR, et al. The suicidal risks and treatments, seek medications from multi-disciplinary. Cent Nerv Syst Agents Med Chem. 2016;16(3):231-239

8. Lu DY, Zhu PP, Wu HY, et al. New modes of suicide/mental disorder diagnostics and therapeutics. In: Da-Yong Lu, editor. Suicide risks and treatments, new ideas and future perspectives. New York, US: Nova Science Publishers; 2017:51-62.

9. Lu DY, Wu HY, Yarla NS, et al. HAART in HIV/AIDS treatments, future trends. Infect Disord Drug Targets. 2018;18(1):15-22.

10. Serafini G, Salano P, Amore M. Suicidal ideation: a comprehensive overview. In: Bradley Weaver, editor. Suicidal Ideation: Predictors, Prevalence and Prevention. US: Nova Science Publishing; 2015:1-42.

11. While D, Bickley H, Roscoe A, et al. Implementation of mental health service recommendations in England and Wales and suicide rates, 1997 2006: a cross-sectional and before-and-after observational study. Lancet. 2012;379(9820):1005-1012.

12. Lu DY, Lu TR, Lu Y, et al. Introduction for suicide study. Journal Metabolic Syndrome. 2017;6(2):227. 
13. Lu DY, Zhu PP, Wu HY, et al. Human suicide risk and treatment study. Cent Nerv Syst Agents Med Chem. 2018;18(3):206-212.

14. Melton J. Hip fracture; a worldwide problem today and tomorrow. Bone. 1993;14 Suppl 1:S1-S8.

15. Silva DMW. Diagnosis of osteoporosis; bone mineral density, risk factors, or both. EC Orthopaedics. 2018;9(7):500-502.

16. Lu DY, Che JY, Shen Y. Osteoporosis in old women, therapeutic selection. EC Orthopaedics. 2018;9(7):386.

17. Lu DY, Che JY, Shen Y. Clinical treatments of osteoporosis, how to target co-morbidities. EC Orthopaedics. 2018;9(11):781-782.

18. Putta S, Peluso I, Yarla NS, et al. Diabetes mellitus and male aging, pharmacotherapeutics and clinical implications. Curr Pharm Des. 2017;23(41):6321-6346.

19. Lu DY, Che JY, Yarla NS, et al. Type 2 diabetes study, introduction and perspective. The Open Diabetes Journal. 2018;8:13-21.
20. Lu DY, Che JY, Yarla NS, et al. Type 2 diabetes treatment and drug development study. The Open Diabetes J. 2018;8:22-33.

21. Lu DY, Che JY, Lu Y, et al. An overview of obesity. Metabolomics. 2018;8(2):200.

22. Lu DY, Che JY, Wu HY, et al. Obesity, risks and managements. Metabolomics. 2018;8(1):e156.

23. Lu DY, Che JY, Lu TR, et al. Pathology and treatments of obesity. Trends in Medicine. 2018;8(5):157.

24. Lu DY, Lu TR, Xu B, et al. Perspectives of personalized cancer therapy. Adv Biotechnology \& Microbiology. 2017;4(3):555637.

25. Lu DY, Lu TR, Che JY, et al. Individualized cancer therapy, future approaches. Current Pharmacogenomics \& Personalized Medicine. 2018;16(2):156-163. 